Technical Paper

DOI: http://dx.doi.org/10.6108/KSPE.2014.18.1.091

\title{
$\mathrm{KSLV}-\mathrm{I}$ 상단 킥모터 개발 개요
}

이한주 ${ }^{\mathrm{a}, *} \cdot$ 이정호 $^{\mathrm{a}} \cdot$ 오승협 $^{\mathrm{a}}$

\section{Brief Summary of KSLV-I Upper Stage Kick Motor Development}

\author{
Hanju Lee ${ }^{\mathrm{a}, *} \cdot$ Jung Ho Lee ${ }^{\mathrm{a}} \cdot$ Seung Hyub $\mathrm{Oh}^{\mathrm{a}}$ \\ ${ }^{a}$ Propulsion System Department, Korea Aerospace Research Institute, Korea \\ *Corresponding author. E-mail: leehj@kari.re.kr
}

\begin{abstract}
KSLV-I (Korea Space Launch Vehicle-I) upper stage KM (Kick Motor) is a solid propulsion system which consists of igniter, SAD (Safety Arming Device), composite case, and submerged nozzle capable of TVC (Thrust Vector Control) actuation. Each subsystem of KM fulfilled development requirements for achieving a flight mission successfully. We confirmed the successful development of $\mathrm{KM}$ from the $3^{\text {rd }}$ flight test results of NARO on January 30, 2013. This article deals with the requirements of KM and the results on configuration management, mass variation, thrust axis alignment, and major test results and so on.
\end{abstract}

$$
\text { 초 록 }
$$

KSLV-I (Korea Space Launch Vehicle-I) 상단 킥모터는 고체 추진기관으로 점화기와 점화안전장치로 구성된 점화구동부, 복합재 케이스부, 추력벡터제어가 가능한 잠입형 노즐부, 그리고 추진제로 구성되 어 있다. 킥모터를 구성하는 각 서브시스템들은 비행 임무 달성을 위한 개발 요구조건을 만족시켰으며, 2013년 1월 30일 나로호 3차 비행 시험 결과로부터 성공적으로 개발이 완료되었음을 확인할 수 있었 다. 본 논문에서는 킥모터에 대한 요구조건, 요구조건을 만족하기 위한 형상관리, 중량 변화, 추력 축 정렬 결과 및 주요 시험 결과 등에 대해 다루었다.

Key Words: KSLV-I(Korea Space Launch Vehicle-I), Upper Stage(상단), Kick Motor(킥모터)

1. 서 론

Received 3 June 2013 / Revised 5 December 2013 / Accepted 14 December 2013 Copyright (C) The Korean Society of Propulsion Engineers pISSN 1226-6027 / elSSN 2288-4548 / http://journal.kspe.org [이 논문은 한국추진공학회 2013년도 춘계학술대회(2013. 5. 30-31, 부산 해운대 한화리조트) 발표논문을 심사하여 수정 · 보완한 것임.]
KSLV-I 상단 킥모터는 고체 추진기관으로 점 화구동부, 케이스부, 노즐부, 추진제로 구성되어 있다. 점화구동부는 추진제를 점화시키는 장치로 점화기, 점화안전장치, 압력센서와 이들 간의 인 터페이스를 총칭한다. 케이스는 추진제를 저장하 는 용기이며 킥모터 연소 시, 추력을 인터페이스 
구조체에 전달하는 구조물로 비행종단 및 자세 제어를 위한 여러 가지 부품들을 지지한다. 노즐 부는 케이스에 연결되어 고온, 고압의 연소가스 를 팽창시켜서 추력을 발생시키는 장치로 추력 벡터조절 (TVC, Thrust Vector Control)을 통해 서 KSLV-I 2단을 정해진 궤도로 유도하는 역할 을 한다. 추진제는 산화제와 연료의 혼합물로 케 이스 내에 일정한 형태로 충전되어 연소 시에 고압의 가스를 발생시키는 물질이다.

상기 서브시스템들의 조합체인 킥모터 시스템 이 비행 임무 달성을 위해서는 다음과 같은 요 구조건을 만족시켜야 한다.

KSLV-I 상단 킥모터는 작동 환경 (고도 약 $300 \mathrm{~km}$ )에서 총역적과 비추력 요구조건을 만족시 켜야 한다[1]. 이를 위한 내탄도 특성은 최대 추 력 $10,000 \mathrm{kgf}$ 이하이며 점화 30 초 이후 추력의 형상이 점진 감쇄형이 되도록 추진제의 그레인 형상이 설계되었다. 이러한 내탄도 요구조건 이 외에도 정확한 추력의 전달을 위해 형상공차 [2] 를 만족시켜야 하며 연소 시에 연소 불안정성이 발생하지 않아야 한다. 또한 KSLV-I 상단부 구 성품에 대한 환경시험 기준을 만족해야 한다[3].

본 논문에서는 상술한 요구조건을 만족시키기 위한 형상관리, 중량 변화, 추력 축 정렬 결과 및 주요 시험 결과 등을 다룬다.

\section{2. 킥모터 개발 개요}

\section{1 킥모터 형상 및 중량}

지상연소시험용 킥모터를 포함한 모든 킥모터 는 납품 시에 추력 비정렬 오차 범위와 횡방향 무게 중심 오프셋 허용 범위를 만족해야 하며, 이는 킥모터 서브시스템의 제작 단계에서부터 확인, 관리되어 진다. 주요한 형상 관리 항목으 로는 케이스의 후방보스 동심도, 후방보스 평행 도, 노즐목 동심도, 노즐목 대비 확대부 동심도 및 노즐부 누적 롤방향 오차를 들 수 있다[4].

상술한 형상 공차 항목들은 시스템 차원에서 관리되어 지는 주요한 형상 관리 항목들로서 킥
모터 시스템의 형상 공차 관리 기준을 만족시키 지 못할 경우에는 지상 시험 및 비행시험에 적 용할 수 없다. Fig. 1에는 확대비 15인 단축형 노즐을 적용한 지상시험용 모델 8기와 확대비 35 인 노즐을 적용한 모델 6기, 총 14 기의 킥모터 시스템에 대한 형상 공차 모니터링 결과를 도시 하였다. 각각의 측정치를 기준치로 무차원하여 나타내었으며, 허용 공차 내에서 제작되었음을 확인할 수 있다.

Fig. 2와 Fig. 3에 킥모터 단면도와 외형을 도 시하였다. 킥모터 케이스부의 직경은 $0.98 \mathrm{~m}$ 이고 최대 길이 $2.34 \mathrm{~m}$ 이다. 단면도로부터 추진제의 그레인 형상과 플렉서블 씰이 적용된 잠입형 노 즐 구조를 확인할 수 있다. 킥모터 전방부에 설 치된 점화기는 점화 신뢰도를 높이기 위해 설치 된 2기의 점화안전장치 (SAD, Safety Arming Device)에 의해 안전모드에서 장전모드로 변환된 후 착화되는 구조이다.

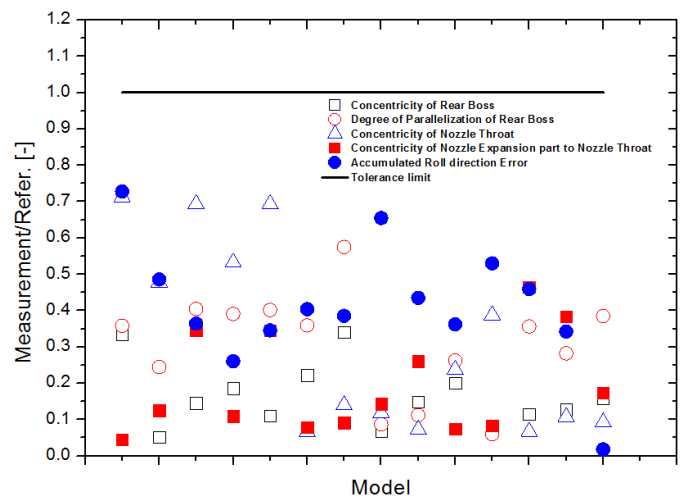

Fig. 1 KSLV-I KM configuration management results.

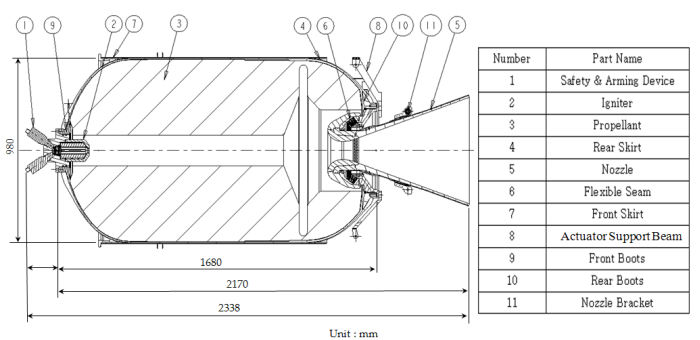

Fig. $2 \mathrm{KM}$ section view. 
추력벡터조절 (TVC)은 노즐부의 브라켓링과 구동기 지지빔에 결합되는 구동기에 의해 수행 되어 진다. 킥모터에 장착된 구동기와 관련 유압 배관들은 Fig. 3에서 확인할 수 있다. Fig. 3과 같은 $3 \mathrm{D}$ 모델 자료를 활용하여 킥모터 자체의 형상관리 뿐만 아니라 상단 타 시스템과의 기계 적 인터페이스 관리를 수행하였으며, 전체 상단 시스템의 무게중심과 관련된 배치 설계도 수행 하게 된다.

또한 상단부의 기체축과 킥모터의 추력 축이 요구조건 내로 정렬되지 않을 경우엔 상단 자세 제어 오차가 허용 범위를 초과할 수 있게 된다. 이러한 오차를 최소화하기 위해 제작 완료된 킥 모터는 지상연소시험과 비행 시험 전에 추력 비 정렬 오차 요구조건 내로 피치 및 요방향에 대 한 추력 축 정렬을 수행하였다[5]. Fig. 4로부터 지상 연소 시험용 모델과 비행 시험용 모델은 추력 축 정렬 요구조건을 만족함을 알 수 있다.

킥모터 개발에 있어 형상 뿐만 아니라 중량도

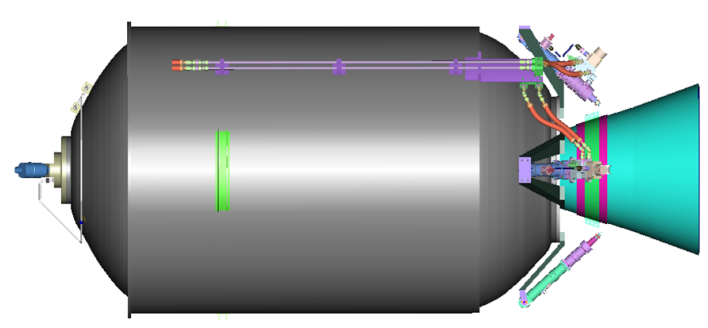

Fig. 3 KM 3D model.

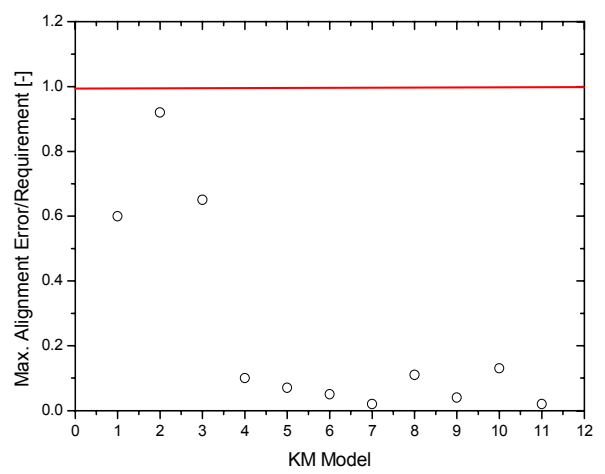

Fig. $4 \mathrm{KM}$ thrust axis alignment results.

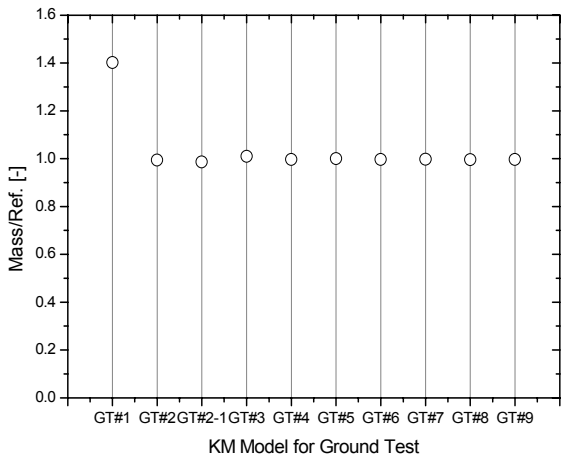

Fig. 5 Structure mass of $\mathrm{KM}$ for ground test.

중요한 관리 항목이다. 비행용 킥모터의 구조체 (점화구동부, 케이스부, 노즐부) 중량은 목표 중 량 대비 99.4 99.9\%에 해당하며, 추진제는 목 표 충전량 대비 $0.1 \%$ 오차로 충전되었다. 10 회의 지상연소시험용 킥모터의 구조 중량은 Fig. 5와 같다.

첫 지상 연소 시험용 모델의 경우 내탄도 설 계 검증이 주요 목적으로 구조체의 경우, 안정성 을 고려하여 케이스의 내열재와 와인딩이 비행 용 대비 대폭 보강되었으며, 케이스 전/후방 보 스와 노즐 연결부 및 노즐 확장부의 소재가 비 행용과 달리 강재가 사용되었다. 이후 모델들은 목표 중량을 달성하기 위해 감량한 결과들로 개 발 과정에서 비행용 대비 보강된 구조가 사용된 적이 있지만, 최종적으론 비행용과 동일한 구조 체를 적용, 지상연소시험을 통해 열적, 구조적 안전성을 검증하였다.

\section{2 이송 및 보관}

(주)한화 대전 공장에서 점화안전장치와 구동 기를 제외하고 조립 완료된 킥모터 조합체는 지 상연소시험 및 고고도 모사 지상연소시험을 위 해 국방과학연구소 안흥시험장과 고흥 항공센터, 비행 시험을 위해 나로 우주센터로 이송된다. 이 송 시에는 전용 이송 치구에 장착하여 해당 시 험장으로 이송하게 되며, 이송 중 3축 가속도계 를 설치하여 가속도를 측정하며, 충격지시계를 별도로 설치하여 이송 중에 순간적인 충격 유무 
를 확인하게 된다. Fig. 6에는 킥모터 모델별 $(\mathrm{GT}, \mathrm{HT}, \mathrm{FM})$ 이송 시의 최대 이송 가속도를 도시하였으며, 제한 요구조건을 만족시킴을 확인 할 수 있다. 또한 보관 요구조건에 준하는 온/ 습도 요구조건을 만족시켰으며, 2008년부터 순차 적으로 나로 우주센터 고체모터동에 입고된 비 행용 킥모터는 비행 시험 전까지 장시간 보관되 는 데, 보관 요구조건을 만족시키기 위해서 항온 챔버 내에서 온/습도를 유지 관리하였다.

\section{3 주요 시험 결과}

Fig. 7에는 주요 시험 일정을 도시하였다. 실 물형 킥모터에 대한 시험 전에 축소형 모델 및 열특성 확인을 위한 모델을 활용한 시험이 2004 년부터 2005년까지 수행되었으며, 시험 결과들은 실물형 킥모터의 설계에 반영되었다. 실물형 킥 모터의 지상연소시험은 2006년 1월에 시작하여 총 11회의 시험을 수행하였으며, 고고도 모사 지 상연소시험은 2007년 8월과 9월에 각 1회씩 총 2회를 수행하였다. 개발 단계에서의 지상연소시 험은 국방과학연구소 안훙 시험장에서 GT\#5까 지 수행하였으며, 이후 수행된 지상연소시험은 추진기관 인증단계의 시험으로 상단 탑재대 (VEB, Vehicle Equipment Bay)와 연계하여 고훙 항공센터에서 수행하였다. 고고도 모사 지상연소 시험 역시 상단 추진기관에 대한 최종 인증시험 차원의 연소시험으로 고고도 압력 조건을 모사 하기 위해 킥모터를 디퓨져에 연결한 후 연소 시험을 수행하였다.

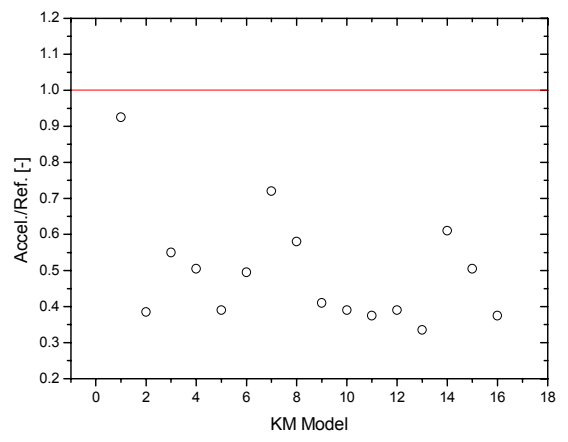

Fig. 6 Maximum acceleration during KM transportation.

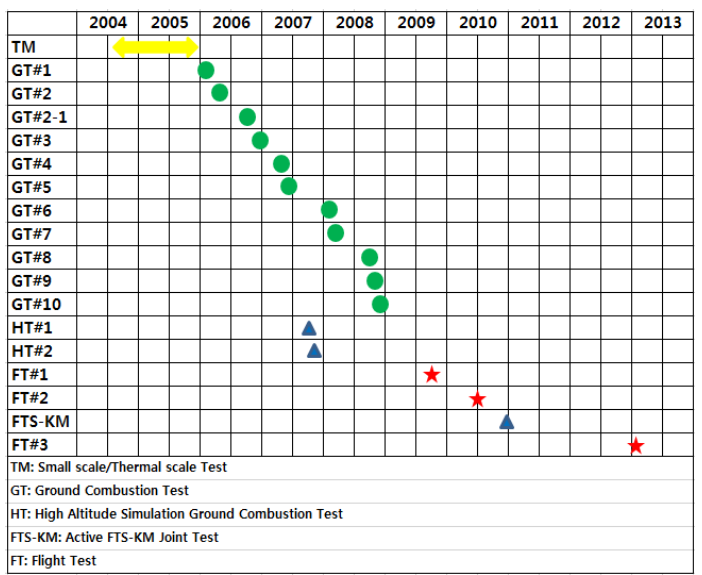

Fig. $7 \mathrm{KM}$ test schedule.

비행시험은 2009년, 2010년, 그리고 2013년 총 3회가 수행되었다. 1차 비행 시험에서는 나로호 가 발사대에서 이륙한 후 395초 경과된 후에 킥 모터는 정상 점화되었으며, 비록 한쪽 페어링 미 분리로 인해 과도한 롤 방향 자세 제어를 수행 하게 되었으나 킥모터는 정상 작동한 것으로 확 인되었다. 2차 비행 시험에서는 1단 비행 구간에 서 문제가 발생되어 킥모터는 정상적으로 점화 되지 않았으며, 3차 비행 시험에서는 모든 비행 이벤트에서 성공적으로 작동된 것으로 확인되었 다. 또한 킥모터 케이스부에 장착된 비행종단시 스템 작동이 킥모터 추진제에 미치는 영향을 파 악하기 위한 FTS-KM 시험이 나로 우주센터에서 수행되었으며, 비행종단시스템이 작동되면 킥모 터의 추진제는 즉시 점화가 되는 것으로 확인되 었다.

GT\#5 의 내탄도 결과 [1]를 기준으로 하였을 때, 10 회의 지상연소시험 결과들은 총역적의 경 우 $-2.5 \% \sim 0.8 \%$ 범위에, 비추력의 경우 $-2.6 \%$ $0.8 \%$ 범위에, 최대 추력의 경우 $-5.5 \%$ 5\%의 범위에 있는 것으로 확인되었으며, Fig. 8에 확 장비 15 인 노즐을 적용한 지상연소시험 결과를 도시하였다. 11회의 지상연소시험 결과는 GT\#2 를 제외하곤 정상적인 연소 종료로 시험을 마칠 수가 있었다. GT\#2 시험에서는 점화 후 약 30초 경에 킥모터 전방부로부터 화염이 분출되어 킥 모터 및 시험장 일부가 파손되었다. 킥모터의 추 


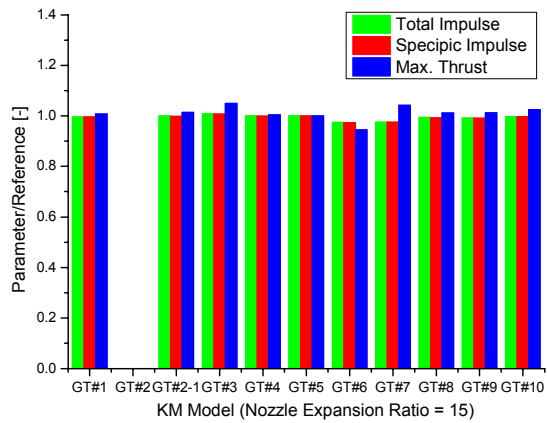

Fig. $8 \mathrm{KM}$ test results (nozzle expansion ratio 15 ).

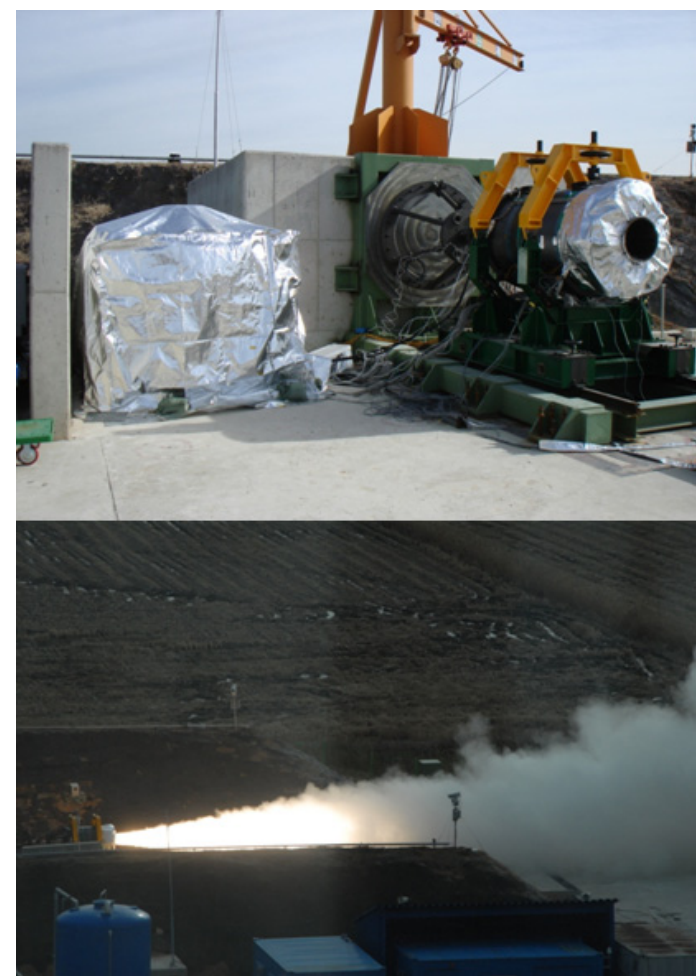

Fig. 9 KM GT\#6 test.

진 성능을 높이기 위해 추진제에 다량의 알루미 늠을 포함시키는데, 연소 시에 산화알루미늠 액 적으로 배출되게 된다. 이 때 일부 노즐로 배출 되지 못하고 킥모터 내부에 적층되는 액적을 슬 래그라고 표현하는데, 케이스 전방돔에 슬래그가 적층되고 이로 인해 내열재를 태우게 되어 설계

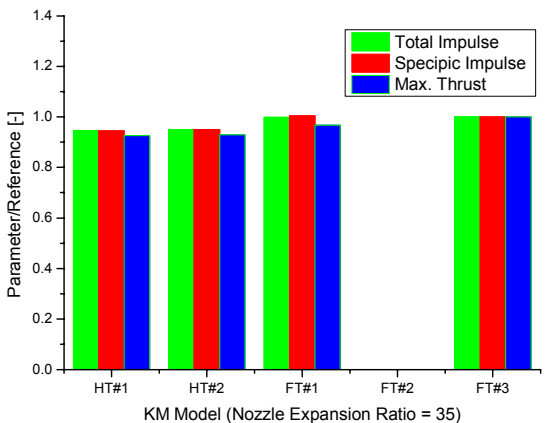

Fig. $10 \mathrm{KM}$ test results (nozzle expansion ratio 35 ).

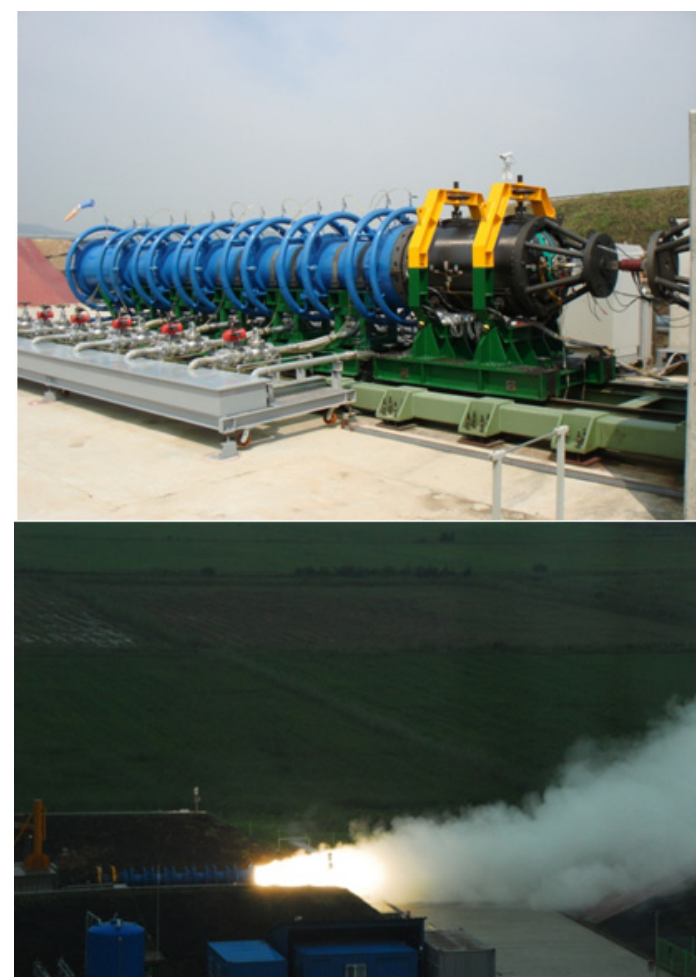

Fig. $11 \mathrm{KM} \mathrm{HT \# 2} \mathrm{test.}$

된 내열재 두께가 충분치 않게 되었다. 이러한 사고는 킥모터를 수평 거치한 상태에서 수행한 지상 연소 시험에서만 발생될 수 있는 문제로 슬래그가 중력 방향으로 흘러 내려 축적되었기 때문이다. 비록 비행 시험에서는 발생되지 않을 것이지만, 성능 확인을 위한 추후 지상연소시험 


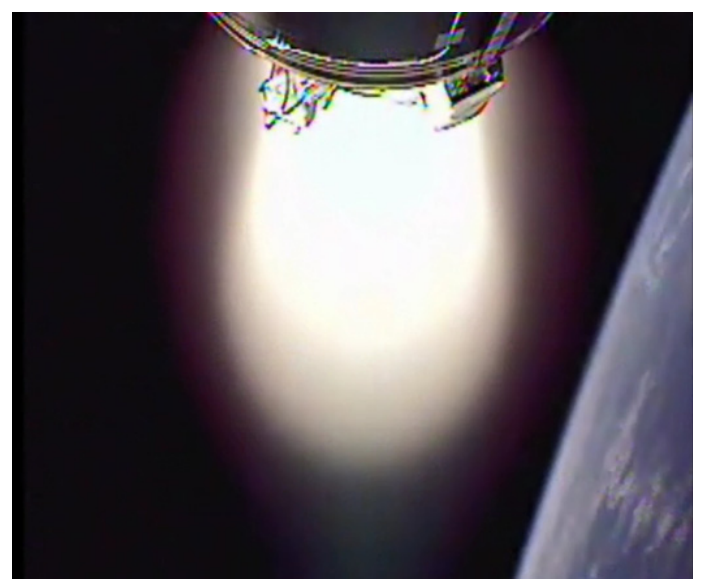

Fig. 12 Onboard camera freeze-frame after KM ignition.

에서의 열적 안정성을 고려하여 내열소재의 완 충재를 보강하여 이후 시험에서는 정상적으로 연소 시험을 마무리할 수 있었다.

Fig. 9에는 고흥 항공센터에서 수행한 VEB 연 계 킥모터 지상연소시험 (GT\#6) 의 시험 전과 연소 중의 사진을 도시하였다.

비행용 노즐을 적용한 시험의 결과는 3 차 비 행시험 (FT\#3) 의 내탄도 결과를 기준치로 했을 때, 4 회의 시험 결과는 총역적의 경우 $-5.4 \%$ $-0.18 \%$ 범위에, 비추력의 경우 $-5.5 \%$ $0.42 \%$ 범 위에, 최대 추력의 경우 $-7.4 \% \sim-3.3 \%$ 의 범위에 있는 것으로 확인되었다. 또한 3 차 비행시험 $(\mathrm{FT} \# 3)$ 의 경우, 비행 시험 결과 대비 예측치의 최대 오차가 총역적, 비추력, 작동 시간에 있어 각각 $0.06 \%, 0.03 \%, 0.3 \%$ 인 것으로 확인되었으 며, Fig. 10에 확장비 35인 비행시험용 노즐을 적용한 시험결과를 도시하였다.

Fig. 11에는 고흥 항공센터에서 수행한 2차 고 고도 모사 지상연소시험 (HT\#2) 의 시험 전과 연소 중의 사진을 도시하였으며, Fig. 9의 지상 연소시험과 달리 킥모터 후단에 디퓨져가 설치 되어 있다. Fig. 12에는 상단에 탑재된 카메라 화면으로 이륙 395초 후, 약 $300 \mathrm{~km}$ 고도에서
킥모터가 정상 점화되었음을 알 수 있다.

\section{3. 결 론}

KSLV-I 상단 킥모터를 구성하는 각 서브시스템 들은 비행 임무 달성을 위한 개발 요구조건을 만 족시켰으며, 2013년 1월 30일 나로호 3차 비행 시 험 결과로부터 성공적으로 개발이 완료되었음을 확인할 수 있었다.

본 논문에서는 킥모터에 대한 요구조건, 요구조 건을 만족하기 위한 형상관리, 중량 변화, 추력 축 정렬 결과 및 주요 시험 결과 등에 대해 다루 었다.

\section{References}

1. Cho, I.H., Lee, W.B., Kim, Y.M., and Cho, G.R., "Design and Test of KSLV-I Kick Motor," Proceeding of the 2007 KSAS Fall Conference, pp. 1510-1504, 2007.

2. Kim, J.H., GD14530PA00000-0001(B), Korea Aerospace Research Institute, Internal Document, 2006.

3. Chun, Y.D., SP51400PA00000-0001, Korea Aerospace Research Institute, Internal Document, 2004.

4. Lee, H., Jung, D.H., and Oh, S.H., "Configuration Tolerance for KSLV-I Kick Motor System," Aerospace Engineering and Technology, Vol. 10, No. 2, pp. 128-132, 2011.

5. Lee, H., Jung, D.H., and Oh, S.H., "KSLV-I Kick Motor System Thrust Axis Alignment," Aerospace Engineering and Technology, Vol. 9, No. 2, pp. 138-142, 2010. 